\title{
Study of efficacy of mifepristone as inducing agent for mid trimester medical termination of pregnancy in women with previous cesarean section
}

\section{Shaila Chikkagowdra*, Vanaja Doddaiah, Veerendrakumar CM}

Department of Obstetrics and Gynecology, VIMS, Ballari, Karnataka, India

Received: 06 July 2016

Accepted: 05 August 2016

\section{*Correspondence:}

Dr. Shaila Chikkagowdra,

E-mail: shailagbgoud@gmail.com

Copyright: () the author(s), publisher and licensee Medip Academy. This is an open-access article distributed under the terms of the Creative Commons Attribution Non-Commercial License, which permits unrestricted non-commercial use, distribution, and reproduction in any medium, provided the original work is properly cited.

\begin{abstract}
Background: Second trimester pregnancy induction in the scenario of a prior caesarean birth has become an increasingly common due to improved prenatal screening methods. The objective of this study was to evaluate efficacy of Mifepristone as inducing agent for mid trimester medical termination of pregnancy in women with previous cesarean section.

Methods: Mifepristone $200 \mathrm{mg}$ orally was given to 37 women willing for abortion between 13 to 20 weeks of gestation with previous LSCS for various indications during study period. After 36 hour misoprostol /oxytocin was given. Outcomes like rate of complete abortion, rupture, induction abortion interval and side effects were noted.

Results: Mean induction abortion interval (IAI) was $8.2+/-3.8$ hours. $80 \%$ of cases between 13 to 16 weeks aborted within first 10 hours. None of the cases had incomplete abortion, rupture or significant side effects.

Conclusions: Combination regimen has abortion rate as higher as $99-100 \%$ and median induction to abortion interval is as low as 6 hours. Second trimester abortion in prior cesarean section women should be carried out with caution.
\end{abstract}

Keywords: Medical abortion, Second trimester abortion, Mifepristone, Misoprostol, Cesarean section

\section{INTRODUCTION}

Cesarean Section is the most frequent surgical procedure performed in obstetrics and gynecology. Second trimester pregnancy induction in the scenario of a prior caesarean birth has become an increasingly common due to improved prenatal detection of fetal malformation by ultrasound and serum screening tests. Although many studies have demonstrated the small risk of complications for vaginal birth at term after a prior CS and the safety of early medical abortion. ${ }^{1-3}$ The experience of a midtrimester pregnancy termination in women with prior uterine scar is more limited. ${ }^{4}$ Uterine rupture, hemorrhage and hysterotomy/hysterectomy remain uncommon and inevitable complications of any termination method used in second-trimester pregnancy. Various protocols have been described, but few studies have documented the efficacy of an abortion protocol combining of mifepristone and prostaglandin analogue (RCOG 1997). Our protocol achieved a complete abortion rate with lower morbidity with termination of pregnancy between 13 to 20 weeks, hence reporting the series.

\section{METHODS}

This single arm study was conducted in the Department of Obstetrics and Gynecology, VIMS, Ballari from January 2013 to December 2015. There were 37 abortions between 13 to 20 weeks of gestation with previous LSCS for various indications mentioned. In all these cases, pretreatment counseling was done, clinical assessment and laboratory investigations confirmed the fitness for medical method of termination. Severe anemia, deranged coagulation profile and women not 
willing for medical methods were excluded. Mifepristone $200 \mathrm{mg}{ }^{6}$ was administered orally on empty stomach for all the recruited subjects after obtaining informed written consent. After $36 \mathrm{hr}$ misoprostol or oxytocin was administered based on improvement in the Bishop's score. oxytocin 10 units infusion was started If the cervix was dilated and membranes were bulging titrating the dose depending on the response or 200 microgram of sublingual misoprostol was used fourth hourly if still the cervix was not dilated. In cases where there was failure to improve the Bishops score trans cervical Foley"s bulb was placed. The Foley's catheter was left in place till its expulsion or 12 hour whichever was earlier. This was followed by sublingual misoprostol 200 microgram every fouth hourly. Injection tramadol was used as analgesic and injection ceftriaxone was the antibiotic given. All these cases were followed for the end results and data was documented.

Demographic data like age, parity, obstetric data including previous obstetrical outcome, number of previous LSCS, time since the surgery, indication for termination were noted. Outcomes like rate of complete abortion, rupture, induction abortion interval, hemorrhage requiring transfusion, need of hysterotomy, side effects such as pyrexia, nausea, vomiting and diarrhea, infectious morbidity and mortality were noted.

The collected data was entered into an excel sheet. After appropriate data cleaning, the data sheet was transferred and analyzed using SPSS software version - 20. Descriptive statistics were used to describe the study variables of the subjects. To compare the categorical qualitative data variables among the two study groups, Chi-square test and $\mathrm{Z}$ tests were used.

\section{RESULTS}

Total 37 women with prior caesarean underwent induction of abortion between 13 to 20 weeks of gestation during the study period. $83.7 \%$ of were between 21 to 30 years (Table 1). $40 \%$ were between 13 to 16 weeks and $35 \%$ were 20 weeks (Table 2 ). $62 \%$ were $2^{\text {nd }}$ gravida (Table 3). $83 \%$ had 1 prior LSCS and $16 \%$ had 2 prior LSCS (Table 4). 50\% of terminations were due to anencephaly and other various anomalies not compatible with life and $35 \%$ were because of IUFD (Table5). $65 \%$ of cases combination of mifepristone and misoprostol was used. In $21 \%$ cases mifepristone, Foleys bulb and misoprostol was used. In $13.5 \%$ cases oxytocin was sufficient to expel the products. $62 \%$ of them aborted within 10 hours of PGs after priming and rest of them in next 10 hours (Table 7). Mean induction abortion interval (IAI) was 8.2+/- 3.8 hours (Table 7). $80 \%$ of cases between 13 to 16 weeks aborted within first 10 hours. $62 \%$ of 20 weeks aborted within 10 hours (Table 8). In our study none of the cases had incomplete abortion and rupture due to agents used for termination.
Table 1: Age wise distribution of the patients.

\begin{tabular}{|lll|}
\hline Age wise distribution of the patients \\
\hline Age group & Frequency & Percent \\
\hline$\leq 20$ years & 5 & 13.5 \\
\hline $21-25$ years & 17 & 45.9 \\
\hline $26-30$ years & 14 & 37.8 \\
\hline$>30$ years & 1 & 2.7 \\
\hline Total & 37 & 100.0 \\
\hline Mean \pm SD & $25.03 \pm 3.53$ & \\
\hline
\end{tabular}

Table 2: Distribution of the patients based on gestational period.

\begin{tabular}{|c|c|c|}
\hline \multicolumn{3}{|c|}{$\begin{array}{l}\text { Distribution of the patients based on gestational } \\
\text { period }\end{array}$} \\
\hline Gestation period & Frequency & Percent \\
\hline 13 - 16 weeks & 15 & 40.5 \\
\hline 17 - 19 weeks & 9 & 24.3 \\
\hline 20 weeks & 13 & 35.1 \\
\hline Total & 37 & 100.0 \\
\hline Mean \pm SD & $18.41 \quad 4.11$ & \\
\hline
\end{tabular}

Table 3: Gravida wise distribution of the patients.

\begin{tabular}{|lll|}
\hline Gravida wise distribution of the patients \\
\hline Gravida & Frequency & Percent \\
\hline Gravida 2 & 23 & 62.2 \\
\hline Gravida 3 & 9 & 24.3 \\
\hline Gravida $>3$ & 5 & 13.5 \\
\hline Total & 37 & 100.0 \\
\hline
\end{tabular}

Table 4: Distribution of the patients based on previous no. of LSCS.

\begin{tabular}{|c|c|c|}
\hline $\begin{array}{l}\text { Distribution of the p: } \\
\text { LSCS }\end{array}$ & ts based on & jious $\mathbf{n}$ \\
\hline Previous no. of LSCS & Frequency & Percent \\
\hline 1 & 31 & 83.8 \\
\hline 2 & 6 & 16.2 \\
\hline Total & 37 & 100.0 \\
\hline
\end{tabular}

Table 5: Distribution of the patients based on indication of abortion.

\begin{tabular}{|lll|}
\hline Indication of abortion & Frequency & Percent \\
\hline Anencephaly & 6 & 16.2 \\
\hline Anhydromnios & 2 & 5.4 \\
\hline Other Anomalies & 13 & 37.8 \\
\hline IUFD & 13 & 35.1 \\
\hline PROM & 2 & 5.4 \\
\hline Total & 37 & 100.0 \\
\hline
\end{tabular}

None of the cases had significant side effects like pyrexia, nausea, vomiting and diarrhoea. 2 women required blood transfusion not because of haemorrhage but due to pre-existing anemia. $100 \%$ of the cases had 
complete abortion, none required check curettage. As antibiotic coverage was given, none had significant sepsis or morbidity. $50 \%$ had minor degree of pain which alleviated after injection tramadol.

Table 6: Distribution of the patients based on method of termination.

\begin{tabular}{|ll|l|}
\hline Method of termination & Frequency & Percent \\
\hline Mifepristone + misoprostol & 24 & 64.9 \\
\hline $\begin{array}{l}\text { Mifepristone + Foleys bulb } \\
\text { + misoprostol }\end{array}$ & 8 & 21.6 \\
\hline Mifepristone + Oxytocin & 5 & 13.5 \\
\hline Total & 37 & 100.0 \\
\hline
\end{tabular}

Table 7: Distribution of the patients based on induction abortion interval.

\begin{tabular}{|c|c|c|}
\hline Induction abortion interval & Frequency & Percent \\
\hline $1-9$ hours & 24 & 64.9 \\
\hline $10-20$ hours & 13 & 35.1 \\
\hline Total & 37 & 100.0 \\
\hline Mean \pm SD & 8.223 .81 & \\
\hline
\end{tabular}

Table 8: Gestation versus induction abortion interval among the patients.

\begin{tabular}{|lllll|}
\hline Parameters & $\begin{array}{c}1-9 \\
\text { hours }\end{array}$ & $\begin{array}{l}10-20 \\
\text { hours }\end{array}$ & NA & Total \\
\hline $\begin{array}{l}13-16 \\
\text { weeks }\end{array}$ & $12(80.0)$ & $3(20.0)$ & $0(0.0)$ & $15(100)$ \\
\hline $\begin{array}{l}17-19 \\
\text { weeks }\end{array}$ & $3(33.3)$ & $5(55.6)$ & $1(11.1)$ & $9(100)$ \\
\hline 20 weeks & $8(61.5)$ & $5(38.5)$ & $0(0.0)$ & $13(100)$ \\
\hline Total & $23(62.2)$ & $13(35.1)$ & $1(2.7)$ & $37(100)$ \\
\hline
\end{tabular}

Figures in parenthesis are percentages.

Table 9: Major complications.

\begin{tabular}{|ll|}
\hline Haemorrhage & Frequency \\
\hline Incomplete & None \\
\hline Rupture & None \\
\hline Hysterotomy & None \\
\hline Total & None \\
\hline
\end{tabular}

\section{DISCUSSION}

Uterine rupture during labor induction abortion has been reported with almost all agents including high-dose oxytocin ethacridine lactate, urea/PGF2 $\alpha$, saline/PGF2 $\alpha$ and misoprostol. ${ }^{7-11}$ Approximately half have been in unscarred uteri, and most have occurred in women with pregnancies of 18-24 weeks gestational age. ${ }^{12-16}$ For second trimester abortion (13-24 weeks of gestation), medical abortion with mifepristone followed by a prostaglandin analogue is an appropriate method and has been shown to be safe and effective, according to WHO and the RCOG. ${ }^{17-22}$ It has been well proven that pretreatment with mifepristone 24-48 hours before prostaglandin administration increases the success rate, shortens the induction-to-abortion interval and reduces the amount of prostaglandins required in the second trimester in unscarred uteri. ${ }^{23,24}$

In our series women with previous LSCS ,mifepristone $200 \mathrm{mg}$ was given 36 hours prior to the misoprostol or oxytocin and found that none of the cases had incomplete abortion or rupture probably because we had ensured improvement in Bishop's score even by putting Foley's bulb before administration of prostaglandins. None had significant side effects like pyrexia, nausea, vomiting and diarrhea probably due to lower dose of misoprostol. Two of our subjects required blood transfusion not because of hemorrhage but due to pre-existing anemia. All of them had complete abortion confirmed by placental examination and ultrasound, none required check curettage. It could be speculated that, with the combination of mifepristone and misoprostol, the incidence of uterine rupture should be lower because of the advantage of cervical dilatation facilitated by mifepristone even before the uterus begins to contract to expel its contents.

Routine surgical evacuation of uterus fallowing medical abortion is not required. ${ }^{26}$ It is noteworthy that the mean dose of misoprostol necessary to induce abortion was lower with pre-treatment with mifepristone. This is important since prolonged induction of labor up to $24 \mathrm{hrs}$ has been correlated with a higher risk of uterine rupture. ${ }^{27}$ However, comparison of our data with those published elsewhere is difficult because protocols have varies widely with regard to administration mode type and dosage. $^{28}$ In series using extra-amniotic perfusion of PGE2 for abortion between 16 and 27 weeks gestation. ${ }^{29}$ Observed no case of uterine rupture. In 600 women who underwent abortion after 15 weeks with oxytocin $3.8 \%$ of them had uterine rupture. ${ }^{30}$ In our series none had rupture.

The main limitations of this study are its size, single arm and usage of customized protocols within the study. Larger randomized trials will be required to determine safety of combination protocol comparison with other proposed protocols for abortion in women with previous cesarean section.

\section{CONCLUSION}

Combination regimen has abortion rate as higher as 99$100 \%$ and median induction to abortion interval is as low as 6 hours. Second trimester abortion in prior cesarean section women should be carried out with caution.

\section{ACKNOWLEDGMENTS}

Thanks to Dr Raghavendra Bellara, Associate Professor, Department of P and SM, VIMS, Ballari - 583104 for guidance in statistical analysis. 
Funding: No funding sources

Conflict of interest: None declared

Ethical approval: The study was approved by the Institutional Ethics Committee

\section{REFERENCES}

1. Miller DA, Diaz FG, Paul RH .Vaginal birth after cesarean: a 10- year experience. Obstet Gynecol. 1994;84(2):255-8.

2. Gao P, Wang P. Clinical observation on termination of early pregnancy of 213 cases after caesarian section with repeated use of mifepristone and misoprostol. Shengzhi Yu Biyun. 1999;10(4):227-33.

3. Gautam R, Agrawal V. Early medical termination pregnancy with methotrexate and misoprostol in lower segment cesarean section cases. J Obstet Gynaecol Res. 2003;29(4):251-6.

4. Rosen MG, Dickinson JC, Westhoff CL. Vaginal birth after cesarean: a meta-analysis of morbidity and mortality. Obstet Gynecol. 1991;77(3):465-70.

5. Dodd JM, Crowther CA. Misoprostol versus cervagem for the induction of labour to terminate pregnancy in the second and third trimester: a systematic review. Eur J Obstet Gynecol Reprod Biol. 2006;125(1):3-8. Epub 2006 Feb 7.

6. Royal college of obstetricians and gynaecologists. the care of women requesting induced abortion. Guidelines No.7. London; 2004.

7. Yapar EG, Senoz S, Urkutur M, Batioglu S, Gokmen O. Second trimester pregnancy termination including fetal death: comparison of five different methods. Eur J Obstet Gynecol Reprod Biol. 1996;69(2):97102.

8. Edwards RK, Sims SM. Outcomes of secondtrimester pregnancy terminations with misoprostol: comparing 2 regimens. Am J Obstet Gynecol. 2005;193(2):544-8.

9. Malhotra N, Chanana C. Silent rupture of unscarred uterus: an unusual presentation at second trimester abortion. Arch Gynecol Obstet. 2007;275(4):283-5.

10. Isada NB, Pryde PG, Johnson MP, Hallak M, Blessed WB, Evans MI. Fetal intracardiac potassium-chloride injection to avoid the hopeless resuscitation of an abnormal abortus. I. Clinical issues. Obstet Gynecol. 1992;80:296-9.

11. Dickinson JE, Evans SF. A comparison of oral misoprostol with vaginal misoprostol administration in second-trimester pregnancy termination for fetal abnormality. Obstet Gynecol. 2003;101:1294-9.

12. Al-Hussaini TK. Uterine rupture in second trimester abortion in a grand multiparous woman. A complication of misoprostol and oxytocin. Eur J Obstet Gynecol Reprod Biol. 2001;96:218-9.

13. Berghahn L, Christensen D, Droste S. Uterine rupture during secondtrimester abortion associated with misoprostol. Obstet Gynecol. 2001;98:976-7.

14. Chen M, Shih JC, Chiu WT, Hsieh FJ. Separation of cesarean scar during second-trimester intravaginal misoprostol abortion. Obstet Gynecol.1999;94:840.
15. Letourneur B, Parant $\mathrm{O}$, Tofani V, Berrebi A. Uterine rupture on unscarred uterus following labor induction for 2 nd trimester termination of pregnancy with oral misoprostol: conservative management. J Gynecol Obstet Biol Reprod (Paris). 2002;31(4):3713.

16. Nayki U, Taner CE, Mizrak T, Nayki C, Derin G. Uterine rupture during second trimester abortion with misoprostol. Fetal Diagn Ther. 2005;20:469-71.

17. Royal College of Obstetricians and Gynaecologists. The Care of Women Requesting Induced Abortion. Guidelines No.7. London, 2004.

18. Grimes DA, Schulz KF, Cates W Jr, Tyler CW Jr. Mid-trimester abortion by dilatation and evacuation: a safe and practical alternative. N Engl J Med. 1977; 296(20):1141-5.

19. Autry AM, Hayes EC, Jacobson GF, Kirby RS. A comparison of medical induction and dilation and evacuation for secondtrimester abortion. Am J Obstet Gynecol. 2002;187(2):393-7.

20. Report of Confidential Enquires into Maternal Deaths in the United Kingdom (1994-1996) Why Mothers Die. Department of Health. London: Her Majesty's Stationary Office. 1997.

21. Lalitkumar S, Bygdeman M, Gemzell-Danielsson K. Mid-trimester induced abortion: a review. Human Reproduction Update. 2007;13(1):37-52.

22. World Health Organization. Unsafe Abortion: Global Estimates of the Incidence of Unsafe Abortion and Associated Mortality in 2000. $4^{\text {th }}$ ed. Geneva7 WHO, 2004.

23. Thong KJ, Baird DT. A study of gemeprost alone, dilapan or mifepristone in combination with gemeprost for the termination of second trimester pregnancy. Contraception.1992;46(1):11-7.

24. Ho PC, Tsang SS, Ma HK. Reducing the induction to abortion interval in termination of second trimester pregnancies: a comparison of mifepristone with laminaria tent. $\mathrm{Br} \quad \mathrm{J}$ Obstet Gynaecol. 1995;102(8):648-51.

25. Ho PC, Ngai SW, Liu KL, Wong GC, Lee SW. Vaginal misoprostol compared with oral misoprostol in termination of second-trimester pregnancy. Obstet Gynecol. 1997;90(5):735-8.

26. El-Refaey H, Templeton A. Induction of abortion in the second trimester by a combination of misoprostol and mifepristone: a randomized comparison between two misoprostol regimens. Hum Reprod. 1995;10(2):475-78.

27. Dickinson JE, Evans SF. The optimization of intravaginal misoprostol dosing schedules in secondtrimester pregnancy termination. Am J Obstet Gynecol. 2002;186:470-4.

28. De Heus R, Graziosi GC, Christiaens GC, Bruinse HW, Mol BW. Medical management for termination of second and third trimester pregnancies:a comparison of strategies. Eur J Obstet Gynecol Reprod Biol. 2004;116:16-21.

29. Debby A, Golan A, Sagiv R, Sadan O, Glezerman M. Midtrimester abortion in patients with a previous 
uterine scar. Eur J Obstet Gynecol Reprod Biol. 2003;109:177-80.

30. Chapman SJ, Crispens M, Owen J, Savage K. Complications of midtrimester pregnancy termination: the effect of prior cesarean delivery. Am J Obstet Gynecol. 1996;175:889-92.

Cite this article as: Chikkagowdra $\mathrm{S}$, Vanaja $\mathrm{V}$, Veerendrakumar CM. Study of efficacy of Mifepristone as inducing agent for mid trimester medical termination of pregnancy in women with previous cesarean section. Int $\mathrm{J}$ Reprod Contracept Obstet Gynecol 2016;5:3051-5. 